\title{
Caracterização de adolescentes em medida de internação: Estudo na área da moralidade
}

\author{
Characterization of adolescents in confinement measure: A study in the area of morality
}

\author{
Marcelo Menezes Salgado ${ }^{[a] 1}$, Heloisa Moulin de Alencar ${ }^{[b]}$
}

\footnotetext{
${ }^{[a]}$ Mestre em Psicologia pela Universidade Federal do Espírito Santo (Ufes), Vitória, ES - Brasil, e-mail: marcelomsalgado@gmail.com

${ }^{[b]}$ Doutora em Psicologia pela Universidade de São Paulo (USP), professora do Programa de Pós-Graduação em Psicologia da Universidade Federal do Espírito Santo (Ufes), Vitória, ES - Brasil, e-mail: heloisamoulin@gmail.com
}

Recebido: 21/12/2010 Received: 12/21/2010

Aprovado: 16/11/2011 Approved: 11/16/2011

\begin{abstract}
Resumo
0 presente artigo consiste em um estudo sobre a caracterização de adolescentes que cumprem medidas socioeducativas de internação. Nosso objetivo foi conhecer a realidade dos internos por intermédio de: idade; delito cometido; processo escolar; participação em curso e/ou oficina na instituição. Cabe destacar que nosso interesse foi analisar os dados de caracterização dos jovens a partir de referenciais da psicologia da moralidade. Participaram da investigação 30 adolescentes com idade entre 16 e 17 anos, do sexo masculino, internos em uma unidade do Instituto de Atendimento Socioeducativo do Espírito Santo (Iases), na região metropolitana da grande Vitória (ES). Realizamos entrevistas individuais, de acordo com o método clínico proposto por Piaget (1926/s.d.; 1932/1994). Por intermédio dos resultados encontrados, constatamos que a maioria dos adolescentes estuda e faz cursos e/ou oficinas. Quanto aos delitos cometidos, os internos mencionam, dentre outros: "roubo ou furto", "tráfico de drogas ou associação ou uso", "homicídio ou latrocínio" e "tentativa de homicídio ou tentativa de latrocínio". Importante destacar que os dados referentes a escola, cursos e/ou oficinas sugerem uma carência de relações cooperativas e uma falta de integração de outrem nos projetos pessoais dos internos. Ainda constatamos que os adolescentes conferem grande atenção aos seus projetos de vida. Ressaltamos a existência de argumentações morais no repertório de jovens que cometeram infrações. Tal fator evidencia a importância de trabalhos que investiguem os valores morais de adolescentes envolvidos pelo crime e violência, problematizando, inclusive, os ditames presentes nos planos moral e ético de tais jovens.
\end{abstract}

Palavras-chave: Adolescentes. Medida socioeducativa de internação. Moral e ética.

\section{Abstract}

This article presents a study on the characterization of adolescents who are under educational confinement measures. Our goal was to understand the reality of the inmates through the means of age; offense; school process, participation in a course and/or workshop in the institution. It is worth noting that our interest was to analyze the characterization data of young people through the psychology of morality referential. Thirty adolescents participated in the investigation, aged

1 O autor agradece o apoio financeiro da Coordenação de Aperfeiçoamento de Pessoal de Nível Superior - Capes. 
between 16 and 17, male inmates in a unit of the Institute of Socio-Educational Services of the Espirito Santo (Iases) in the metropolitan region of Vitoria (ES). We conduct interviews according to the clinical method proposed by Piaget (1926/sd,1932/1994). Through the results we found, we observed that most adolescents study and take courses and workshops. As for offenses committed, the inmates mentioned, among others, 'larceny or theft', 'drug dealing or usage or association', 'murder or violent robbery' and 'attempted murder or attempted violent robbery'. It's important to highlight that the data regarding the school, courses and workshops suggest a lack of cooperative relationships and a lack of integration of others in the personal projects of the inmates. Further, we found that adolescents pay great attention to their life projects. We emphasize the existence of moral arguments in the repertoire of young people who committed infractions. This factor highlights the importance of studies that investigate the moral values of adolescents involved by crime and violence, questioning, including, the dictates present in the moral and ethical plans of these young people.

Keywords: Adolescents. Educational confinement measure. Moral and ethics.

\section{Introdução}

Atualmente, estudos com adolescentes em medidas socioeducativas têm obtido grande destaque devido à importância que a Ciência confere à compreensão de indivíduos que estão envolvidos em processos relacionados à violência e à criminalidade. A partir de uma revisão de literatura, vimos que o estudo do adolescente infrator é um tema deveras investigado, embora ainda esteja longe de ser esgotado pela comunidade acadêmica em sua produção. Constatamos, no entanto, que pesquisas com adolescentes em medidas socioeducativas de internação são menos frequentes.

Em nossa revisão ${ }^{2}$, encontramos que apenas 12 trabalhos foram realizados sobre os jovens com medidas de internação (Almeida, 2002; Aranzedo, 2006; Aun, 2005; Branco \& Wagner, 2009; Branco, Wagner \& Demarchi, 2008; Guará, 2000; Mosqueira, 2008; Noguchi, 2006; Oliveira, 2002; Oliveira \& Vieira, 2006; Padovani, 2003; Pereira, 2002), o que demonstra a necessidade da continuidade de investigações sobre o tema.

Diante do exposto, nosso objetivo foi conhecer melhor a realidade de adolescentes internos em uma instituição de medidas socioeducativas por intermédio de informações como: idade; delito cometido; processo escolar; participação em curso e/ou oficina na instituição, bem como o motivo de sua participação em atividades oferecidas na instituição de internação como cursos e/ou oficinas, visando fornecer informações recentes sobre o assunto em pauta. Cabe destacar, ainda, que nosso interesse foi analisar os dados de caracterização dos jovens internos a partir de referenciais da psicologia da moralidade. Tendo em vista tal objetivo, nossa abordagem baseia-se nos fundamentos teóricos de Piaget (1932/1994) e La Taille (2006). Assim sendo, a seguir, discorremos sobre as principais contribuições dos referidos autores para o presente estudo.

De acordo com a teoria de Piaget (1932/1994), o campo da moralidade é inicialmente concebido como um conjunto de deveres, e, nesse sentido, para compreensão do fenômeno moral, seria necessário estudar a gênese do "sentimento de obrigatoriedade", verificado, por meio da razão, no homem. Segundo o referido autor, o desenvolvimento moral é caracterizado pela evolução de uma tendência moral heterônoma para uma autônoma. Os estudos piagetianos evidenciam que é a qualidade do tipo de respeito que a pessoa experimenta com os demais que permitirá o estabelecimento dessas tendências.

\footnotetext{
2 Realizamos buscas de publicações dos últimos 15 anos nas bases BVS-Psi, Biblioteca digital - Unicamp (Teses e Dissertações), Biblioteca digital - USP (Teses e Dissertações), SciELO, PePSIc - Periódicos Eletrônicos em Psicologia e Periódicos Capes (Cambridge Journals Online, PsycARTICLES, PsycINFO, ScienceDirect [Elsevier]).
} 
Nesse sentido, ele passará de um respeito unilateral a um respeito mútuo. No unilateral, teríamos o estabelecimento de relacionamentos nos quais um "manda" e os demais "obedecem", uma vez que o respeito é unidirecional, isto é, da pessoa submissa para aquela que detém a autoridade. Por sua vez, no respeito mútuo ocorre a consideração da igualdade entre os pares, existindo um respeito compartilhado entre as pessoas em seus relacionamentos, sendo os mesmos permeados por acertos e trocas mútuas.

$\mathrm{Na}$ abordagem moral piagetiana, falamos em uma fase heterônoma (moral do dever) e em outra autônoma (moral do bem). Na primeira fase, deparamo-nos com uma criança que respeita as regras impostas pelos adultos em virtude do medo que possui de uma suposta punição ou por receio de perder o amor das pessoas que representam a figura de autoridade. Assim, segundo Piaget (1932/1994), na referida fase as regras são seguidas em virtude da ocorrência de sentimentos como o medo e o amor, dentre os quais o medo recebe destaque. Segundo o autor, há a observância de algo por temor do castigo que se pode sofrer ou, ainda, em virtude do medo de perder o amor daquele que representa a autoridade. Nesse prisma, configura-se o respeito unilateral que citamos; essa fase é caracterizada pela ocorrência de uma relação desigual, na qual a criança percebe a autoridade como direitos e deveres distintos aos seus. Em síntese, na heteronomia o que se estabelece é uma relação de coação da criança pelo adulto. Para Piaget (1932/1994, p. 284), o desenvolvimento da moralidade avança na medida em que

o elemento quase material de medo, que intervém no respeito unilateral, desaparece então progressivamente em favor do medo totalmente moral de decair aos olhos do indivíduo respeitado: a necessidade de ser respeitado equilibra, por conseguinte, a de respeitar, e a reciprocidade que resulta desta nova relação basta para aniquilar qualquer elemento de coação.

Nesse sentido, avançamos para o que Piaget (1932/1994) denomina autonomia. Nessa fase, as crianças agem por princípios de reciprocidade, e as relações se caracterizam pela cooperação. As regras são seguidas por meio do reconhecimento de sua importância para as relações sociais e, dessa forma, são compreendidas como passíveis de mudança para que se experimente uma convivência harmoniosa entre os pares. Piaget (1932/1994) demonstra que as regras são cumpridas porque foram construídas e apreendidas conjuntamente, de modo a favorecer o convívio social mútuo. Assim, o que predomina, na fase evidenciada, é o respeito mútuo, oriundo da nova condição de igualdade, estabelecida por uma adequada interação.

Interessante destacar que a obra de Piaget (1932/ 1994) sobre a moral confere grande ênfase ao papel que a socialização, em seus diversos contextos, possui no desenvolvimento da moralidade das pessoas. 0 autor explicita a importância do convívio social para que se alcance uma moral autônoma. É o processo de socialização que pode influenciar o sujeito a se tornar autônomo, fazendo com que ele reflita sobre as regras sociais, respeitando-as porque reconhece que elas são o melhor para si e para a sociedade. Em tal âmago, entendemos que ao expormos os dados de caracterização dos adolescentes internos que entrevistamos, poderemos discutir os aspectos morais que porventura existam no complexo desenvolvimento psicológico dos referidos jovens.

Assim, por exemplo, sob o prisma dos processos escolares, consideramos que é interessante expor um estudo desenvolvido por La Taille, Flor e Fevorini (1991), o qual aborda a temática do desenvolvimento moral e a sua articulação com problemas educacionais, refletindo sobre a obrigatoriedade do fazer escolar. Os autores, ao investigarem em alunos a questão do "dever estudar", consideraram, em sua análise, três classes distintas de justificativas de por que estudar, são elas: (1) "dever circular" - remete à ausência de objetivos exteriores que faça do estudo um meio para atingi-los, por exemplo, o estudar somente para passar de ano; (2) "dever hipotético" - no qual o estudo é importante para que se alcancem objetivos externos, porém individuais (exemplo: ter uma profissão); e (3) "dever moral" - em que o estudar é justificado por uma questão interpessoal, isto é, deve-se estudar para fazer o bem às outras pessoas, não possuindo, portanto, um caráter individualista.

Quanto aos resultados encontrados, os autores verificaram a ocorrência de um maior número de argumentos hipotéticos à medida que aumentava a idade dos participantes. Assim, por exemplo, nos adolescentes de 13 e 14 anos observou-se uma maioria de justificativas hipotéticas e uma minoria de morais. La Taille et al. (1991) discutem os dados tendo como fundamento as relações cooperativas piagetianas, refletindo que a grande ocorrência de justificativas hipotéticas sugere o anseio 
legítimo por ter uma vida melhor, todavia individual, o que, grosso modo, poderia evidenciar um certo despreparo para a prática da cidadania e das relações sociais.

Com efeito, alunos que predominantemente utilizam o argumento hipotético em detrimento do moral preocupam-se prioritariamente com um projeto individual e, com isso, deixam de notar a função social do conhecimento. Os autores sintetizam evidenciando que o desenvolvimento da autonomia, conforme Piaget (1932/1994), só poderá ser alcançado por meio de relações sociais de cooperação, as quais não seriam percebidas em indivíduos que utilizem o "dever hipotético" como justificativa. Em face do exposto, uma questão interessante seria conhecer os juízos de adolescentes que cometem infrações no que tange ao "dever estudar". Tais jovens apresentariam justificativas circulares, hipotéticos ou morais? Eis a questão.

Para ampliarmos nossas considerações sobre a questão da moralidade, é necessário, finalmente, trazermos as contribuições de La Taille (2006). 0 autor concebe a hipótese de que para tornar inteligíveis as condutas morais humanas, devem-se compreender as concepções éticas que os mesmos assumem, isto é, se existe uma relação entre os planos moral e ético. La Taille (2006) ao definir moral e ética procura fazê-lo associando-as às perguntas "como devo agir?" e "que vida quero viver?". Segundo ele, a reflexão moral corresponde ao "como devo agir?" e as ponderações sobre a ética às respostas de "que vida que quero viver?"'. Assim, discorrer sobre a moralidade implicaria uma discussão sobre deveres; por sua vez os comentários sobre a ética estabelecem-se a partir das percepções de 'vida boa', isto é, uma vida que vale a pena ser vivida. Por isto, o autor aprofunda suas discussões teóricas, objetivando responder às perguntas do 'plano moral' e do 'plano ético', analisando as formas e conteúdos que esses planos ocupam.

0 referido autor procura demonstrar que o plano da moralidade pode ocupar diversos conteúdos, denotando uma pluralidade de sistemas morais. Entretanto, defende que há uma "forma" presente em todas as morais; dito de outra maneira, haveria algo similar presente em todos os sistemas morais que é o "sentimento de obrigatoriedade". Decerto, para ele, há "mandamentos da consciência que impelem o indivíduo a agir de determinadas formas, e não de outras" (La Taille, 2006, p. 31). Haveria, portanto, um "plano moral" (sentimento de obrigatoriedade) que compreenderia diversos conteúdos, agindo, portanto, nos homens por meio do dever.

Por sua vez, a dimensão ética conduz a outro plano em nossa vida, o 'plano ético' (La Taille, 2006). Em tal plano, o sujeito estabelece uma reflexão sobre uma vida que mereça ser vivida, algo em que o viver tenha sentido, e dessa forma, é remetido a uma percepção de si mesmo, procurando estabelecer ideais que possibilitem a existência de uma vida feliz. Logo, o plano ético preconiza a execução de um projeto que contemple uma vida melhor: somos confrontados a responder à pergunta "Que vida quero viver?". São as respostas para essa pergunta que possibilitarão o despontamento do plano ético rumo a uma existência de maior felicidade. Por conseguinte, é imprescindível destacar que de certo modo as respostas de tal indagação do plano ético remetem-nos à formulação de projetos de vida pessoais; estes, em síntese, referem-se ao "sentido de projetar para o futuro as aspirações e os desejos de realizações que vão sendo construídos no cotidiano, por meio das relações que são estabelecidas das mais diversas formas, nos mais diferentes contextos e pessoas" (Abreu, 2009, p. 17).

Destarte, tendo em vista que o assunto (projetos de vida) pode favorecer a compreensão do plano ético, uma indagação cabível é: a referida pauta evidenciar-se-á na caracterização dos adolescentes investigados? É o que veremos mais adiante. Ademais, como pudemos notar, a teoria de La Taille (2006) leva-nos a interessantes discussões sobre o desenvolvimento moral e, nesse sentido, aguça nossa atenção para a compreensão dos planos moral e ético também em adolescentes em medidas socioeducativas, temática pouco investigada pela ciência em sua produção.

Após mencionarmos os fundamentos teóricos do presente estudo, discorremos sobre o adolescente em medida socioeducativa de internação, comentando a contextualização desses segundo a legislação específica. Por fim, explicitamos a revisão de literatura concernente ao tema, citando as pesquisas associadas ao assunto. Iniciemos, portanto, o desenvolvimento dos referidos tópicos. Para tanto, passemos às considerações que o Decreto-lei 8.609, Estatuto da Criança e do Adolescente [ECA] (1990), estabelece sobre os adolescentes infratores, para que a partir daí possamos discutir a respeito do adolescente em medida socioeducativa de internação. 
Segundo o ECA (1990), quando um adolescente pratica algum delito, aplica-se uma das seguintes medidas socioeducativas: advertência, obrigação de reparar dano, prestação de serviços à comunidade, liberdade assistida, regime de semiliberdade e privação de liberdade em instituições específicas. No que concerne à privação de liberdade, como medida socioeducativa, esta só deve ser efetivada quando as outras propostas não alcançam resultados satisfatórios. Assim sendo, existem critérios e requisitos que devem ser preenchidos para que a medida socioeducativa de privação de liberdade seja aplicada. Em síntese, ela deve ser implementada em casos mais extremos, de ameaças e infrações graves ou violência à pessoa, reincidência e por descumprimento não plausível de medidas socioeducativas anteriores.

Com efeito, há de se esclarecer o que se entende por agressões e infrações graves. Uma reflexão interessante sobre o tema é a que Toledo (2006) apresenta em sua dissertação de mestrado. Ao discorrer sobre o que se pode considerar a respeito da gravidade de infrações, o autor se pauta pela natureza dessas infrações, considerando sua importância criminológica. Segundo Toledo (2006), o primeiro grupo de delitos com maior importância é o dos crimes contra as pessoas (homicídios, por exemplo); em segundo lugar, encontram-se os crimes contra patrimônio (furto, roubo); a seguir, evidenciam-se os crimes contra os costumes (estupro, atentado violento ao pudor, e suas tentativas) e, por último, os crimes contra a saúde pública (porte e tráfico de entorpecente).

Segundo Toledo (2006), os crimes contra as pessoas detêm importância criminológica por apresentarem aspectos sociais importantes, como o valor da vida, os quais indicam o estágio de violência de uma sociedade. Os crimes contra patrimônio possuem importância, segundo o autor, por salientarem fortes indicadores dos problemas concernentes à violência que podem existir no âmbito social; são crimes que se diferenciam de outros no tocante à sua motivação, o ganho financeiro. Quanto aos crimes contra os costumes, Toledo (2006) entende que "sua relevância está, para além da objetividade jurídica focada em relação ao corpo da vítima, no interesse maior tutelado que seria a liberdade sexual" (p. 59). No tocante aos crimes contra a saúde pública, são percebidos com relevante gravidade uma vez que ameaçam a saúde coletiva e, provavelmente, estimulam a criminalidade por intermédio de sua influência na prática de outros delitos.
No entanto, apesar de a medida de internação ser implementada somente em casos de gravidade como os citados, o número de adolescentes sob tais medidas vem aumentando nos últimos anos (Lima, 2006; Rosário, 2004). Segundo dados do Instituto de Pesquisa Econômica Aplicada [Ipea] (2003), no Brasil, havia 9.555 adolescentes em cumprimento de medida socioeducativa de internação. Desses, $90 \%$ eram do sexo masculino; com idade entre 16 e 18 anos (76\%); os que não eram brancos chegam a $63 \%$ e dentre essa população de não brancos, 97\% eram afrodescendentes; 49\% não trabalhavam; $51 \%$ não frequentavam a escola; $90 \%$ não concluíram o Ensino Fundamental; 81\% viviam com a família na época em que praticaram o ato infracional; $66 \%$ moravam com famílias de renda mensal com até dois salários mínimos e aqueles que moravam com famílias que não possuíam renda mensal fixa somavam 12,7\%; e 85,6\% eram usuários de drogas. Os delitos praticados por esses adolescentes, segundo o Ipea (2003), são: roubo (29,6\%), homicídio $(18,6 \%)$, furto $(14,0 \%)$, tráfico de drogas $(8,7 \%)$, latrocínio (5,8\%), estupro/atentado violento ao pudor $(3,7 \%)$ e lesão corporal (3,3\%). No que se refere aos delitos praticados por adolescentes internos em instituições, queremos ressaltar os estudos de Assis e Souza (1999) e de Priuli e Moraes (2007).

Assis e Souza (1999), quando investigaram a infração juvenil nos estados do Rio de Janeiro e Pernambuco, destacaram algumas particularidades. A pesquisa evidenciou que em terras fluminenses o delito mais cometido era o roubo/furto $(34,7 \%)$, seguido de tráfico de drogas $(30,4 \%)$ e homicídio/ latrocínio (26\%); e, ainda, em Pernambuco, na primeira posição destaca-se o roubo com $46,7 \%$ e logo após o homicídio/latrocínio (40\%).

Priuli e Moraes (2007), por sua vez, ao estudarem adolescentes em conflitos com a lei, inclusive o perfil infracional desses, também indicam a predominância, na realidade daqueles jovens, do mesmo grupo de delitos percebidos por Assis e Souza (1999), a saber: roubo/furto com 70,8\%, homicídios e congêneres com $20,9 \%$ e ações relacionadas ao universo de drogas que contabilizaram 8,3\%. Apesar de algumas diferenças, os dados desses estudos sugerem similaridade com aqueles evidenciados pelo Ipea (2003). Ressaltamos, ainda, que tais pesquisas foram realizadas em espaços de tempo distintos, por conseguinte, apresentam semelhança em seus dados, evidenciando pouca variação no que tange à época de suas realizações. 
Como visto até aqui, o tema em foco é deveras complexo, demandando, portanto, novas investigações e estudos sobre a realidade dos adolescentes em medidas socioeducativas de internação para que, assim sendo, novos dados estejam disponíveis na academia e nos setores sociais. Portanto, esperamos que a apresentação dos resultados e a discussão evidenciada no presente artigo contribuam para que a comunidade acadêmica e o poder público possam obter uma melhor compreensão de alguns dos aspectos essenciais à vida dos jovens que cometem infrações.

\section{Metodologia}

A realização da coleta de dados de nossa investigação foi implementada em uma unidade socioeducativa masculina de internação não provisória, situada na região metropolitana da Grande Vitória (ES), que atende jovens de 15 a 18 anos incompletos. Participaram da investigação 30 adolescentes com idade variando entre 16 e 17 anos, do sexo masculino, que no momento da coleta de dados estavam em cumprimento de medidas socioeducativas de internação em um setor do Instituto de Atendimento Socioeducativo do Espírito Santo (Iases).

Em nosso trabalho, utilizamos uma entrevista fundamentada a partir do método clínico piagetiano (Piaget, 1926/s.d.; 1932/1994), privilegiando a coleta de dados acerca da caracterização dos adolescentes em medidas socioeducativas, buscando evidenciar dados relevantes para a melhor compreensão dos dinamismos dos referidos participantes no tocante ao seu desenvolvimento. Destarte, o nosso instrumento objetivou a coleta sobre informações gerais dos internos, como por exemplo: idade, delito cometido que culminou na entrada do jovem na instituição de cumprimento de medida socioeducativa de internação, processo escolar e atividades realizadas na unidade (cursos e oficinas).

As entrevistas realizadas com os participantes foram individuais, tendo sua análise realizada, prioritariamente, de forma qualitativa, sem prejuízo de uma referência quantitativa (em termos percentuais) dos dados considerados relevantes na discussão dos resultados. É necessário evidenciar que nossa pesquisa orientou sua análise conforme a proposta metodológica de Delval (2002).

\section{Resultados e discussão}

Nos próximos parágrafos, procuramos apresentar ao leitor os resultados acerca da caracterização dos jovens entrevistados, objetivando fornecer uma visualização dos aspectos concebidos como relevantes para a compreensão dos dados coletados a esse respeito.

0 primeiro dado a ser apresentado é relativo à idade dos adolescentes, a qual varia entre 16 e 17 anos. Assim sendo, averiguamos que $60 \%(n=18)$ dos jovens estavam, no momento da entrevista, com 17 anos; o restante, $40 \%(\mathrm{n}=12)$ tinha 16 anos. Verificamos, então, uma predominância de entrevistados com 17 anos; contudo com uma frequência não muito maior do que a outra faixa de idade. É interessante dizer que, na unidade onde foi realizada a coleta, a maioria dos internos, segundo dados da equipe técnica da unidade socioeducativa, pertencia a tais idades, e totalizavam $63,3 \%$ dos internos que se encontravam na instituição. Tal constatação sugere uma semelhança com as informações nacionais, já que, segundo dados oficiais do Ipea (2003), $52 \%$ de adolescentes em medidas socioeducativas possuíam idade entre 16 e 17 anos em 2002.

A concentração de jovens presos na referida faixa etária parece ser mesmo recorrente, vejamos exemplos: Oliveira e Assis (1999), ao estudarem adolescentes infratores do Rio de Janeiro, verificaram um total de $61 \%$ de internos, com idade entre 16 e 18 anos; Aranzedo (2006), ao investigar homicidas juvenis presos, na região metropolitana da Grande Vitória (ES), encontrou em sua amostra $75 \%$ de participantes com 16 e 17 anos. Outros estudos também apresentam a mesma constatação, ou seja, uma maioria de jovens na faixa etária supracitada: Almeida (2002), Assis e Souza (1999) e Priuli e Moraes (2007).

Passamos, agora, a relatar os conteúdos relacionados ao delito cometido pelo adolescente e que culminou com sua entrada na instituição de medida socioeducativa. Os participantes mencionaram um total de 57 delitos cometidos, os quais originaram oito categorias de respostas. Nossos dados permitiram averiguar que roubo ou furto foi a categoria que obteve o maior percentual de respostas ( $n=15 ; 26,3 \%$ ). A seguir, também com frequência em destaque, aparece a referência ao tráfico de drogas ou associação ou uso (n = 13; 22,8\%). Por sua vez, a resposta homicídio ou latrocínio $(\mathrm{n}=9 ; 15,8 \%)$ 
evidencia-se na terceira posição, sendo sucedida por tentativa de homicídio ou tentativa de latrocínio $(\mathrm{n}=7 ; 12,3 \%)$. Com escores abaixo dos 10\%, aparecem porte ilegal de arma (n = 5; 8,8\%), formação de quadrilha $(\mathrm{n}=4 ; 7,0 \%)$, sequestro relâmpago $(\mathrm{n}=2$; $3,5 \%)$ e quebra de liberdade assistida $(\mathrm{n}=2 ; 3,5 \%)$. É importante destacar que as citações remetidas a homicídio ou latrocínio somadas ao congênere tentativa de homicídio ou tentativa de latrocínio resultam em $28,1 \%$ ( $n=16$ ), sumarizando que ações relacionadas ao homicídio ou latrocínio têm maior incidência nos adolescentes investigados.

Ainda fazendo referência aos delitos cometidos pelos jovens pesquisados, podemos evidenciar outra configuração da incidência dos crimes cometidos pelos nossos entrevistados. Em primeiro lugar, temos as ações relacionadas a homicídios, latrocínios e suas tentativas, com 28,1\% $(n=16)$ das respostas, seguido dos crimes ligados a roubos/ furtos ( $\mathrm{n}=15 ; 26,3 \%)$ e na terceira posição o tráfico de drogas, bem como o uso e ações relacionadas ( $\mathrm{n}=13 ; 22,8 \%$ ). Com o intuito de compararmos os nossos resultados, por meio desta configuração, com dados de outras pesquisas, é importante salientar quais os delitos de maior ocorrência encontrados por outros autores. Os estudos de Almeida (2002), Guará (2000), Oliveira (2002) e Priuli e Moraes (2007) observam que a ordem de incidência dos crimes mais cometidos pelos adolescentes pesquisados compõe-se de (1) roubos/furtos; (2) homicídios, latrocínios e suas tentativas e (3) tráfico de drogas, uso e ações relacionadas. Contudo, Assis e Souza (1999), Oliveira e Assis (1999), Pereira (2002) e Toledo (2006) verificaram que os crimes mais cometidos pelos jovens por eles investigados são, respectivamente: (1) roubos/furtos; (2) tráfico de drogas, uso e ações relacionadas; e (3) homicídios, latrocínios e suas tentativas.

Ante o exposto, constatamos que existe uma prevalência quanto aos tipos de infrações executadas por adolescentes, constando sempre, nas primeiras posições, de: furtos, roubos e assaltos; homicídio, latrocínio e suas tentativas; e o tráfico de drogas, bem como o uso e ações relacionadas. A diferença é percebida apenas na disposição da ordem de incidência dos delitos evidenciados, contudo, os dados parecem reforçar uma tendência da predominância, em primeiro lugar, de delitos relacionados a roubo/furtos/assaltos, sendo que em segundo e terceiro lugares parece haver uma alternância entre os outros dois quesitos.
Mediante tal constatação, é interessante buscar a interpretação da consonância dos dados quanto à incidência, prioritária, do grupo de delitos em enfoque. Presumimos que o resultado obtido possa relacionar-se à aplicação do Decreto-lei 8.609, Estatuto da criança e do adolescente [ECA] (1990), sobre a medida socioeducativa de internação que normatiza as medidas privativas de liberdade que serão aplicadas somente em casos de contravenções graves.

Como apresentado anteriormente, definimos as infrações graves como sendo aquelas que detêm grande importância criminológica (Toledo, 2006), as quais geralmente incidem sobre os delitos relacionados à vida (por exemplo, homicídios), bem como a categoria de roubos/furtos/assaltos e, ainda, aos delitos relacionados à droga (tráfico/porte/uso).

Assim, tomando a referida discussão sobre a gravidade dos delitos e tendo em vista os pressupostos do ECA (1990) quanto à aplicação da medida de internação, verificamos que os dados encontrados pelos estudos ora citados, inclusive os da atual investigação, evidenciam que os delitos mais cometidos que culminaram na internação do adolescente parecem ser parcialmente explicados por meio dessa correlação. Ou seja, a prevalência de um grupo de delitos percebida nas primeiras posições - a saber, roubo/furtos, homicídio/latrocínio e ações relacionadas a drogas - pode estar relacionada à tentativa do Estado em cumprir as resoluções normativas, com a pena adequada, quando do surgimento da prática de tais contravenções, pelo menos no que diz respeito aos jovens por nós entrevistados.

Após a discussão dos delitos verificados em nossa investigação, passemos à apresentação dos resultados relativos ao processo escolar em que estão inseridos nossos participantes. Sob a indagação se naquele momento estudava ou não, verificamos que $76,7 \%(\mathrm{n}=23)$ responderam positivamente e os que afirmaram não estudar contabilizavam 23,3\% $(n=7)$. A seguir, àqueles que diziam estudar, questionamos sobre a motivação para tal ação. Os argumentos totalizaram um número de 157 justificativas, que geraram nove categorias. As duas primeiras categorias quase se igualam quanto ao número de respostas. A primeira delas, atuar em uma ocupação profissional $(\mathrm{n}=34 ; 21,6 \%)$, faz referência à possibilidade de aquisição de atividade remunerada, ao ser uma pessoa trabalhadora, bem como à questão do crescimento interno no seu emprego (subir de hierarquia). 0 segundo fundamento, viabilizar uma 
vida próspera para si $(\mathrm{n}=33 ; 21,0 \%)$, diz respeito à obtenção de bem-estar e coisas boas, como, por exemplo, bens, futuro melhor, dinheiro e estrutura de vida adequada. A outra justificativa direciona-nos para o proporcionar aspecto positivo a familiares $(\mathrm{n}=26 ; 16,6 \%)$, relativo à possibilidade de fomentar auxílio, financeiro ou afetivo, a familiar(es). A quarta categoria enfatiza o ampliar o conhecimento geral ( $\mathrm{n}=15 ; 9,6 \%)$ e comporta justificativas relacionadas à obtenção para si mesmo de conhecimento, cultura e sabedoria. Outro motivo mencionado foi obter diploma $(\mathrm{n}=13$; $8,3 \%$ ) e vincula-se à posse de títulos, por exemplo, na escola e na faculdade. A seguir, temos o promover uma melhor sociabilidade $(\mathrm{n}=7 ; 4,5 \%)$, fazendo alusão ao êxito em relacionamentos interpessoais, isto é, inclusão social, boa comunicação com as pessoas e credibilidade para com as mesmas. As duas justificativas seguintes, suprir uma necessidade $(\mathrm{n}=6 ; 3,8 \%)$ e sair do crime $(\mathrm{n}=4 ; 2,5 \%)$, agregam as menores frequências. Os argumentos da primeira englobam as perspectivas de suprir alguma necessidade futura de uma forma geral, já as justificativas da segunda dizem respeito à saída do crime propriamente dita, traduzindo-se em uma mudança de vida. Por último, temos a categoria outros, cujo percentual foi de $12,1 \%(n=19)$, que engloba os argumentos que não correspondiam a nenhuma das justificativas anteriores e versa sobre: influência familiar ( $\mathrm{n}=3)$, obrigatoriedade do estudo na instituição $(\mathrm{n}=2)$, importância do estudo $(\mathrm{n}=2)$, possibilidade de ser uma pessoa melhor $(\mathrm{n}=2)$, poder ensinar outrem $(\mathrm{n}=2)$, obter melhor rendimento nos estudos $(\mathrm{n}=2)$, aquisição de família $(\mathrm{n}=2)$, boas oportunidades $(\mathrm{n}=1)$, adquirir responsabilidade $(\mathrm{n}=1)$, ocupar a mente $(\mathrm{n}=1)$ e ser independente de outrem $(\mathrm{n}=1)$.

Avaliando os referidos dados, podemos fazer algumas análises sobre os motivos dados pelos nossos participantes em resposta à questão "por que estudar?". Constatamos nos resultados algumas aproximações com o dever-estudar discutido por La Taille et al. (1991). Verificamos que tal discussão exposta pelo autor pode aproximar-se dos resultados encontrados nas justificativas mencionadas pelos nossos participantes tendo em vista que ao analisarmos nossos dados mediante a conceituação do dever circular, hipotético e moral de La Taille et al. (1991), notaremos nas justificativas dos entrevistados que $73,2 \%(n=115)$ foram argumentos hipotéticos. Importante dizer que para definirmos a referida percentagem consideramos as respostas das seguintes categorias: atuar em uma ocupação profissional $(\mathrm{n}=34)$, viabilizar uma vida próspera para si $(\mathrm{n}=33)$, ampliar o conhecimento geral $(\mathrm{n}=15)$, obter diploma $(\mathrm{n}=13)$, suprir uma necessidade $(\mathrm{n}=6)$, sair do crime $(\mathrm{n}=4) \mathrm{e}$, ainda, as categorias detalhadas presentes em outros $(\mathrm{n}=10)-i m$ portância do estudo $(\mathrm{n}=2)$, possibilidade de ser uma pessoa melhor $(\mathrm{n}=2)$, aquisição de família $(\mathrm{n}=2)$, boas oportunidades $(\mathrm{n}=1)$, adquirir responsabilidade $(\mathrm{n}=1)$, ocupar a mente $(\mathrm{n}=1)$ e ser independente de outrem $(\mathrm{n}=1)$.

É importante enfatizar que definimos as justificativas importância do estudo e possibilidade de ser uma pessoa melhor como argumentos hipotéticos, tendo em vista que fazem alusão à aquisição de algum ganho particular por parte do adolescente. Por sua vez, verificamos que $22,3 \%(n=35)$ das justificativas são fundamentos morais, sendo eles os argumentos: proporcionar aspecto positivo a familiares $(\mathrm{n}=26)$ e promover uma melhor sociabilidade $(\mathrm{n}=7)$ e o poder ensinar outrem $(\mathrm{n}=2)$ [a última categoria detalhada mencionada está contida na justificativa outros]. Notamos, ainda, que as únicas referências ao dever circular estão em sete respostas $(4,5 \%)$ encontradas em outros, sendo tais justificativas ligadas a influência familiar $(\mathrm{n}=3)$, obrigatoriedade do estudo na instituição $(\mathrm{n}=2)$ e ao obter melhor rendimento nos estudos $(\mathrm{n}=2)$.

Assim sendo, mediante a correlação de nossos dados com o dever circular, hipotético e moral, conforme apresentados e discutidos em La Taille et al. (1991), poderíamos inferir, a partir das evidências dos resultados, que nossos participantes estariam interessados, prioritariamente, em vantagens pessoais privadas e, dessa forma, desconectados de um projeto cidadão, de uma função social, podendo existir, portanto, uma carência de relações cooperativas.

Concordamos com La Taille et al. (1991) que a referida carência poderia impedir o desenvolvimento da autonomia; no entanto, apesar de não objetivarmos a verificação do desenvolvimento moral no que diz respeito à autonomia e heteronomia (Piaget, 1932/1994), é necessário destacar, quanto aos nossos participantes, que a possível carência da função social em destaque, típica das relações cooperativas, poderia prejudicar o pleno desenvolvimento da autonomia nos jovens entrevistados. Analisando de tal forma, teríamos um grave problema, que é a falta de integração de outrem nos projetos pessoais dos 
internos. Caracterizamo-lo como grave porque a referida falta relaciona-se intimamente com a questão da cidadania e função social, bem como com o desenvolvimento da autonomia.

Chamamos a atenção para o contexto dos nossos participantes, ou seja, adolescentes envolvidos com o crime. Considerando haver indícios de que os jovens não desenvolveram plenamente a cidadania, podemos, ademais, inferir que suas próprias trajetórias pessoais rompem, uma vez que cometeram infrações, com a função social mais ampla, aquela concebida em sociedade, o que parece permitir a ocorrência, predominante, de justificativas relacionadas ao dever hipotético. Todavia, é delicado estabelecer os graus, medidas e ordem de interferência das variáveis envolvidas no processo, ou o que poderia ser determinante nesse caso: Estaria o processo escolar dos internos deficitário? Ou os eventos relacionados à violência seriam determinantes? Fatores familiares podem interferir de alguma forma? Se afirmativo, como tais questões se associam na condução do processo? Presumimos que estabelecer ligações entre esses fenômenos sem maiores cuidados poderia incorrer no fato de uma análise notadamente simplista, na qual provavelmente seriam ignoradas outras possíveis influências.

Ainda, ponderando sobre os motivos evidenciados pelos participantes para estudar, chamamos a atenção para a constatação de que os dados evidenciam a preocupação do adolescente com algum tipo de benefício a ser adquirido por intermédio do estudo. Perceba o leitor que as mesmas justificativas que definimos como hipotéticas $(73,2 \%)$ também estão relacionadas à aquisição de algum tipo de proveito para si. Dessa maneira, temos a constatação de que a maioria das fundamentações mencionadas pelos adolescentes, além de estarem relacionadas a um dever hipotético, também têm seu conteúdo vinculado a alguma vantagem pessoal que o estudo pode trazer aos projetos futuros do participante. É importante salientar que, quando nos remetemos aos projetos estabelecidos pelos adolescentes, estamos fazendo referência a uma parte dos seus "projetos de vida", isto é, às construções cotidianas das aspirações e anseios de realizações pessoais a ser concretizadas em tempos futuros (Abreu, 2009); daremos maior destaque a esse tema, a seguir, na análise dos dados referentes à participação em curso e/ou oficina realizados pelo interno.
Passemos, assim, à apresentação dos resultados sobre a participação em curso e/ou oficina que poderiam fazer parte do cotidiano dos nossos participantes. Constatamos que 70\% $(n=21)$ responderam que participavam de algum curso e/ou oficina, outros 30\% ( $\mathrm{n}=9)$ afirmaram não fazer nenhuma dessas atividades. A seguir, àqueles que responderam positivamente, questionamos sobre qual curso e/ou oficina realizava no momento. Entendemos ser necessário informar ao leitor a existência de participantes que, na questão, mencionaram mais de uma resposta $(n=38)$. Assim sendo, obtivemos o seguinte panorama: $36,8 \%(\mathrm{n}=14)$ afirmaram participar do curso de qualidade no atendimento ao cliente, que versa sobre o mercado de trabalho, qualidade no emprego e atendimento ao cliente; os que realizavam o curso de elétrica contabilizavam $23,7 \%$ ( $\mathrm{n}=9$ ), curso que tinha como enfoque as atividades típicas do trabalho de eletricista; em terceiro lugar $(\mathrm{n}=8 ; 21,1 \%)$, temos os que faziam curso de informática, cujo conteúdo abrangia noções introdutórias da área; na sequência, com 7,9\% (n = 3), temos o curso de panificação (relativo à ministração de técnicas de produção de pães e biscoitos); e, por último, aqueles que participavam de oficina $(\mathrm{n}=4$; $10,5 \%$ ). Dentre as oficinas citadas temos as de artes, música e esportes.

Tendo conhecimento sobre os cursos e oficinas das quais eram partícipes, questionamos os adolescentes sobre sua motivação para fazer a atividade. Assim, contabilizamos o número de 173 justificativas, que geraram dez categorias. Em tais agrupamentos de respostas pudemos verificar que na primeira posição temos a categoria possibilitar ocupação profissional ( $\mathrm{n}=53 ; 30,6 \%)$, que faz referência à possibilidade de aquisição de alguma atividade profissional. Por sua vez, no segundo agrupamento de respostas apresenta-se viabilizar uma vida próspera para si ( $n=44 ; 25,5 \%$ ), que diz respeito à obtenção de bem-estar e coisas boas, como, por exemplo, bens, futuro melhor, dinheiro e estrutura de vida adequada. A próxima categoria versa sobre o ampliar o conhecimento geral ( $\mathrm{n}=20 ; 11,6 \%$ ) e comporta argumentos relacionados à obtenção de conhecimento, cultura e sabedoria. A quarta categoria enfatiza o colaborar em uma melhor visibilidade social $(\mathrm{n}=18 ; 10,4 \%)$, relativo a êxitos em relacionamentos interpessoais, obtenção de elogio, apoio, reconhecimentos, respeito, ser educado. 0 quinto tópico mencionado foi o acatar o contexto da Instituição $(\mathrm{n}=13 ; 7,5 \%)$, que 
versa sobre a obrigatoriedade de fazer cursos ou oficinas na unidade socioeducativa. A seguir, temos o proporcionar aspecto positivo a familiares $(\mathrm{n}=10$; $5,8 \%$ ) fazendo alusão ao auxílio afetivo e financeiro. No sétimo agrupamento de respostas, ser gratuito $(\mathrm{n}=4 ; 2,3 \%)$, temos justificativas relacionadas à ausência de ônus financeiro para a realização da atividade. As próximas duas categorias, sair do crime $(\mathrm{n}=3 ; 1,7 \%)$ e ter preferência $(\mathrm{n}=3 ; 1,7 \%)$, agregam as menores frequências.

Quanto aos conteúdos, a primeira versa sobre a saída do crime propriamente dita, sugerindo uma mudança de vida. Todavia, a segunda, expõe argumentos relacionados à vontade do participante em fazer aquela determinada atividade. Por último, temos a categoria outros, com $2,9 \%(\mathrm{n}=5)$, que engloba ajudar outrem ( $\mathrm{n}=2)$, ajudar os seus estudos $(\mathrm{n}=2)$ e suprir uma necessidade futura $(\mathrm{n}=1)$.

Refletindo sobre os referidos resultados, podemos retomar a discussão sobre o dever hipotético, moral e circular de La Taille et al. (1991), estabelecida quando mencionamos os resultados sobre o processo escolar. Outrossim, na questão relacionada à participação em curso e/ou oficina, verificamos que a maioria das justificativas dos participantes, $85,5 \%(n=148)$ indica que os jovens procuram fundamentar sua participação em cursos e/ou oficinas por meio de argumentos hipotéticos. 0 percentual foi obtido por meio da soma dos argumentos possibilitar ocupação profissional ( $\mathrm{n}=53$ ), viabilizar uma vida próspera para si $(\mathrm{n}=44)$, ampliar o conhecimento geral $(\mathrm{n}=20)$, colaborar em uma melhor visibilidade social $(\mathrm{n}=18)$, ser gratuito $(\mathrm{n}=4)$, sair do crime $(\mathrm{n}=4)$, ter preferência $(\mathrm{n}=3)$, bem como das categorias detalhadas ajudar os seus estudos $(\mathrm{n}=2)$ e suprir uma necessidade futura $(\mathrm{n}=1)$, contidas em outros. Quanto às explicações morais, apuramos um total de $7 \%(\mathrm{n}=12)$ que correspondem a proporcionar aspecto positivo a familiares $(\mathrm{n}=10)$ e ajudar outrem $(\mathrm{n}=2)$ [que se encontra contida em outros]. Os argumentos considerados circulares, que estão dispostos em acatar o contexto da instituição, contabilizam 7,5\% ( $\mathrm{n}=13)$ das justificativas mencionadas. É importante destacar, a partir da exposição dos resultados, que há novamente uma maior frequência de fundamentos considerados hipotéticos, o que nos leva a reforçar a discussão outrora estabelecida a respeito do desenvolvimento da moralidade (Piaget, 1932/1994; La Taille et al., 1991) nos entrevistados, tendo em vista uma suposta preponderância de projetos privados, não coletivos.
Ademais, tais dados parecem enfocar que a participação em curso e/ou oficina se dá na medida em que o mesmo promova algum tipo de vida que seja benéfico a si mesmo, ou seja, determinada vantagem pessoal. Um dado consoante a esse pode ser observado pelo leitor nas justificativas dadas pelos participantes quando mencionaram o porquê de participar das referidas atividades. Conforme podemos observar, notamos que $85,5 \%(\mathrm{n}=148)$ das argumentações, ou seja, a totalidade das justificativas hipotéticas fez referência ao anseio por obter algum proveito para si com o estudo. Com efeito, ao compararmos as motivações expostas nas duas questões, entendemos que parece haver certa preocupação do adolescente com seu futuro, isto é, parece que os resultados enunciam para uma determinada direção dos "projetos de vida" de nossos entrevistados, que perpassaria por planos relacionados ao trabalho, obtenção de recursos financeiros, bem-estar e congêneres. Perceba o leitor que na presente questão analisada (nos resultados do processo escolar há constatações semelhantes) surgem dados que trazem alguns elementos sobre o "projeto de vida" desses jovens (Abreu, 2009).

Assim sendo, se fôssemos analisar os "projetos de vida" dos nossos adolescentes, que não é o objetivo do estudo, teríamos que refletir, sobretudo, a respeito de sua situação social, isto é, um jovem cumpridor de medidas socioeducativas de internação. Entretanto, uma indagação se impõe: em que medida tal realidade afetaria seus projetos futuros? Aliás, que projeções são essas, quais suas gêneses? As referidas projeções estariam relacionadas ao campo ético assumido por esse indivíduo? Entendemos, conforme La Taille (2006) que, ao refletirmos sobre o plano ético, necessariamente, conceberemos como se delineia o plano moral, já que é no plano ético que identificamos as motivações que explicam as ações morais. Destarte, algumas perguntas tornar-se-iam imperativas, como: quais seriam os "projetos de vida" dos jovens que cometem infrações? Haveria evidências de que a história de vida de tais adolescentes, isto é, o fato de terem cometido delitos, interfere em seu "projeto de vida"? Se positivo, como se daria?

Gostaríamos, ainda, de evidenciar dois dos resultados encontrados na caracterização de adolescentes em medidas socioeducativas entrevistados, por ocasião das questões relacionadas ao processo escolar e à participação em curso e/ou oficina. Logo, nossa intenção é enfatizar as argumentações 
que consideramos morais (La Taille et al., 1991) nos resultados emitidos pelos participantes ao discursarem sobre os motivos para estudar e frequentar curso e/ou oficina. Conforme destacado em parágrafos anteriores, pudemos notar que quanto às justificativas para se estudar os adolescentes mencionaram 22,3\% $(n=35)$ de fundamentos morais [argumentos proporcionar aspecto positivo a familiares $(\mathrm{n}=26)$, promover uma melhor sociabilidade $(\mathrm{n}=7)$ e o poder ensinar outrem $(\mathrm{n}=2)$, categoria detalhada disposta em outros]. Por sua vez, nas explicações para a participação em curso e/ou oficina contabilizou-se um total de $7 \%(\mathrm{n}=12)$ desses tipos de argumentações [proporcionar aspecto positivo a familiares $(\mathrm{n}=10)$ e ajudar outrem $(\mathrm{n}=2)$, que se encontram contidas em outros]. A existência de motivos morais faz-nos refletir, novamente, a respeito dos "projetos de vida" dos internos, entretanto, agora sob o enfoque da vinculação desse a outrem.

Apesar de verificarmos que as justificativas em questão possuem uma menor frequência, tais dados nos permitem sugerir - tomando como verdadeira a hipótese que tais explicações morais evidenciariam uma conexão a outrem das projeções futuras dos adolescentes - a existência da possibilidade do desenvolvimento de relacionamentos interpessoais cooperativos e, ainda, o surgimento de elementos que proporcionem a autonomia moral (Piaget, 1932/1994). Dito de outra maneira, estaríamos diante de jovens, outrora praticantes de contravenções, nos quais seria possível a condução de um desenvolvimento moral para a autonomia (Piaget, 1932/1994).

Tais resultados parecem, portanto, direcionar-nos a uma discussão, por demais relevante, sobre a correlação entre as opções de "projetos de vida" dos jovens em medida socioeducativa e a prática da violência; contudo, tendo em vista que a mesma não faz parte dos objetivos da referida pesquisa, deixamos nossa sugestão para que sejam realizadas investigações que enfoquem tal temática.

\section{Considerações finais}

Pudemos descrever características de importância sobre a realidade dos adolescentes em medidas socioeducativas de internação. Destacamos que os dados referentes à escola, cursos e oficinas sugerem uma carência de relações cooperativas e, por conseguinte, a falta de integração de outrem nos projetos pessoais dos internos. Ainda pudemos perceber que os adolescentes conferem grande atenção aos seus projetos de vida. Outro resultado que chama nossa atenção é a existência de argumentações morais no repertório de jovens que cometeram infrações. Tal fator evidencia a importância de trabalhos que investiguem os valores morais de adolescentes envolvidos pelo crime e violência, problematizando, inclusive, os ditames presentes nos planos moral e ético dos jovens.

Por fim, enfatizamos que os dados expostos no artigo levam-nos a destacar ainda mais a importância de estudos que busquem compreender os processos de desenvolvimento dos adolescentes em medidas socioeducativas de internação. Refletimos que podemos evidenciar, dentre outras, duas implicações práticas que o nosso estudo pode fomentar: (1) processos educativos - os resultados que encontramos podem ser levados em consideração pelos educadores dos institutos socioeducativos, a fim de que sejam avaliadas as estratégias de ensino, bem como seus objetivos, visando, por exemplo, um processo formativo atrativo aos jovens, inclusive uma educação em valores morais; e (2) intervenção com os internos da instituição socioeducativa - analisamos que os elementos que aqui dispomos podem orientar, por exemplo, o planejamento de procedimentos dos profissionais que lidam com tais jovens.

Em face do exposto, concebemos que os pontos assinalados poderiam ser algumas das implicações práticas do nosso trabalho. 0 importante é mencionar que colaboramos com a compreensão do universo dos adolescentes em medidas socioeducativas de internação, evidenciando dados que poderão conduzir práticas, reflexões e outras pesquisas. Estamos convictos de que ao fornecermos elementos sobre tais jovens, estamos colaborando, acadêmica e socialmente, para a compreensão mais apurada dos aspectos psicológicos de tais jovens e, por conseguinte, com a redução de processos de violência.

\section{Referências}

Abreu, E. F. (2009). Projetos de vida profissional de estudantes universitários: Um estudo nas perspectivas da moral e da ética. Projeto de Pesquisa para Exame de Qualificação de Doutorado, Vitória, Programa de Pós-Graduação em Psicologia, Universidade Federal do Espírito Santo. 
Almeida, M. M. (2002). Compreendendo as estratégias de sobrevivência de jovens antes e depois da internação na FEBEM de Ribeirão Preto. Dissertação de Mestrado não publicada, Faculdade de Filosofia, Ciências e Letras, Universidade de São Paulo, Ribeirão Preto.

Aranzedo, A. C. (2006). "Nem anjos, nem demônios" Adolescentes autores de homicídio: contexto do delito e representações sociais sobre a vida humana. Dissertação de Mestrado não publicada, Programa de Pós-Graduação em Psicologia, Universidade Federal do Espírito Santo, Vitória.

Assis, S. G., \& Souza, E. R. (1999). Criando Caim e Abel Pensando a prevenção da infração juvenil. Ciência \& Saúde Coletiva, 4(1), 131-144.

Aun, H. A. (2005). Trágico avesso do mundo: Narrativas de uma prática psicológica numa instituição para adolescentes infratores. Dissertação de Mestrado não publicada, Instituto de Psicologia, Universidade de São Paulo, São Paulo.

Branco, B. M., \& Wagner, A. (2009). Os adolescentes infratores e o empobrecimento da rede social quando do retorno à comunidade. Ciência \& Saúde Coletiva, 14(2), 557-566.

Branco, B. M., Wagner, A., \& Demarchi, K. A. (2008). Adolescentes infratores: rede social e funcionamento familiar. Psicologia: Reflexão e Crítica, 21(1), 125-132.

Decreto-lei 8.609: Estatuto da criança e do adolescente. (1990). Recuperado em 15 fev. 2009, de http://www. planalto.gov.br/ccivil_03/Leis/L8069.htm

Delval, J. (2002). Introdução à prática do Método Clínico: Descobrindo o pensamento das crianças (F. Murad, Trad.). Porto Alegre: Artmed.

Guará, I. M. F. R. (2000). O crime não compensa, mas não admite falhas - Padrões morais de jovens autores de infração. Tese de doutorado não publicada, Programa de Estudos Pós-Graduados em Serviço Social, Pontifícia Universidade Católica de São Paulo, São Paulo.

Instituto de Pesquisa Econômica Aplicada [IPEA]. (2003). Mapeamento nacional da situação das Unidades de execução da medida sócioeducativa de privação de liberdade ao adolescente em conflito com a lei. Brasília. Recuperado em 17 mar. 2009, de http://www.ipea. gov.br/pub/td/2003/td_0979.pdf
La Taille, Y. (2006). Moral e Ética: dimensões intelectuais e afetivas. Porto Alegre: Artmed.

La Taille, Y., Flor, C. M., \& Fevorini, L. B. (1991). A obrigatoriedade do ensino segundo alunos de 7 a 14 anos: dever hipotético e dever moral. Cadernos de Pesquisa, 78, 27-39.

Lima, R. C. P. (2006). Mudança das práticas sócio-educativas na FEBEM-SP: As representações sociais de funcionários. Psicologia \& Sociedade, 18(1), 56-62.

Mosqueira, S. M. (2008). À procura de sentido da atenção psicológica com adolescentes em privação de liberdade. Dissertação de Mestrado não publicada, Instituto de Psicologia, Universidade de São Paulo, São Paulo.

Noguchi, N. F. C. (2006). Seguro na FEBEM-SP: Universo moral e relações de poder entre adolescentes internos. Dissertação de Mestrado não publicada, Instituto de Psicologia, Universidade de São Paulo, São Paulo.

Oliveira, M. C. R. (2002). O processo de inclusão social na vida de adolescentes em conflito com a lei. Dissertação de Mestrado não publicada, Faculdade de Filosofia, Ciências e Letras, Universidade de São Paulo, Ribeirão Preto.

Oliveira, M. B., \& Assis, S. G. (1999). Os adolescentes infratores do Rio de Janeiro e as instituições que os "ressocializam" - A perpetuação do descaso. Cadernos de Saúde Pública, 15(4), 831-844.

Oliveira, M. C. S. L., \& Vieira, A. O. M. (2006). Narrativas sobre a privação de liberdade e o desenvolvimento do self adolescente. Educação e Pesquisa, 32(1), 67-83.

Padovani, R. C. (2003). Resolução de problemas com adolescentes em conflito com a lei: Uma proposta de intervenção. Dissertação de Mestrado não publicada, Universidade Federal de São Carlos, São Carlos/SP.

Pereira, F. R. P. (2002). Jovens em conflitos com a lei: A violência na vida cotidiana. Dissertação de Mestrado não publicada, Faculdade de Filosofia, Ciências e Letras, Universidade de São Paulo, Ribeirão Preto.

Piaget, J. (1926). Introdução: Os problemas e os métodos. In Piaget, J. A representação do mundo na criança. (R. Fiúza, Trad.). (pp. 5-28). Rio de janeiro: Record. (Original publicado em 1926).

Piaget, J. (1994). O juízo moral na criança. São Paulo: Summus. (Trabalho original publicado em 1932). 
Priuli, R. M. A., \& Moraes, M. S. (2007). Adolescentes em conflito com a lei. Ciência \& Saúde Coletiva, 12(5), 1185-1192.

Rosário, A. B. (2004). 0 mundo do crime: Possibilidade de intervenção a adolescentes em conflito com a lei. Mental, 2(2), 101-113.

Toledo, G. W. (2006). A delinqüência juvenil no Estado de São Paulo: Característica, freqüência, evolução e tendências observadas entre os anos de 1950, 1960, 1979, 1985, 1995, 2000, 2001 e 2002. Dissertação de Mestrado não publicada, Faculdade de Filosofia, Ciências e Letras, Universidade de São Paulo, Ribeirão Preto. 